\title{
Sea level pressure climatology in black sea region
}

\author{
Sayed Mohammad Hosseini ${ }^{\mathrm{a}}$ and Saeid Movahedi ${ }^{\mathrm{b}^{*}}$
}

${ }^{a} \mathrm{PhD}$ Student, Department of Climatology, Faculty of Planning \& Geography Science, University of Isfahan, Isfahan, Iran ${ }^{b}$ Assistant Professor, Department of Climatology, Faculty of Planning \& Geography Science, University of Isfahan, Isfahan, Iran

\section{H R O N I C L E}

\section{Article history:}

Received June 28, 2013

Received in revised format

19 October 2013

Accepted 20 December 2013

Available online

December 302013

Keywords:

Climatology

Synoptic Analysis

Sea Level Pressure

Black Sea

\begin{abstract}
A B S T R A C T
In the present study, to achieve a comprehensive view of pressure conditions in the Black Sea region, sea level pressure data in Reanalysis II database in National Centers for Environmental Prediction (NCEP)/National Center for Atmospheric Research (NCAR) were used. The data temporal resolution is daily and the spatial resolution is $2.5 \times 2.5$ degrees of arc. The investigated framework covers the areas between -30-70 degrees east longitude and 20-70 degrees north latitude and has dimensions equal $41 \times 21$ pixels consisting of 861 pixels. The studied period of time is 33-year (1979 to 2012) and includes 12419 days and 861 spatial pixels. Therefore, sea level pressure data matrix is $12419 \times 861$, which has 12419 temporal pixels and 861 spatial ones. In other words, the arrangement of the data is S-shaped. The rows of the matrix represent time while columns represent space. At the end, using the cluster analysis, six sea level pressure circulation patterns based on the spatial - temporal features were obtained: Red Sea trough is fall pattern; Iraq trough is spring pattern; Persian Gulf trough is transitional pattern; Persian Gulf strong trough is summer pattern; Caucasian high pressure is fall - winter pattern and the Caucasian Strong high pressure is winter pattern. In most of these patterns, intensive allobaric conditions can be observed in the troughs and ridges.
\end{abstract}

\section{Introduction}

Climate is defined as weather statistical linkage, while weather is controlled by pressure patterns or atmospheric systems (Alijani \& Zahedi, 2002). In fact, climate refers to the long-term weather conditions prevailing over a place (Kaviani \& Alijani, 2003). In another definition, it refers to the behavior of the atmosphere over a period of time (Asakereh \& Razmi, 2011). One of the atmospheric conditions, which forms the climate and is influenced by climate itself is the pressure element. As a result, the study of pressure temporal behavior in a place is known as Pressure Climatology. On the one hand, repeating, changing or sustaining atmospheric systems in every place influences on determining and identifies the climate of that place; while on the other hand, one of the research 
approaches for investigating climatic elements' being influenced is to focus on the atmospheric circulation pattern and the pressure system in the synoptic scale. The justification is that frequency, variation and intensity in pressure systems and the atmospheric circulation pattern play a fundamental role in explaining conditions and climatic elements of a geographical territory (Vicente-Serrano \& Lopez-Moreno, 2006). Therefore, the identification of circulation conditions in any region is the determinant of climatic patterns of that region. It can contribute significantly to knowing better the environmental conditions. Accordingly, by studying the pressure climatology of a region, not only can one recognize the dynamics and behavior of large scale systems, but also it is possible to achieve the possibility of planning based on it. This is because creating spatial and temporal variations takes place in atmospheric systems. In other words, in the occurrence of seasonal or annual cycles in pressure patterns, climatic diversity and sometimes fundamental changes in the most climatic elements such as temperature and rainfall in a region so that the existence of the process of increase or decrease in rainfall and temperature will result in changing in the form of residents of a country. These features, particularly in warm countries, associated with the increasing demands of a growing population, with low water whose water resources rely on precipitation, are considered significantly important (Asakereh \& Razmi, 2011).

Over the recent years, some studies have been conducted regarding circulation patterns and pressure systems. These studies can be summarized in several categories: 1- Simulating sea level pressure pattern (e.g. Corte et al., 1999; Li \& Smith, 2009; Karamouz et al., 2006). 2- Investigating anomaly and distribution of sea level pressure (e.g. Pandzic \& Trninic, 2000; Krichak et al., 2000; Alijani \& Zahedi, 2002; Javanmard et al., 2003; Shabankari \& Halabian, 2012). 3- Synoptic analysis of sea level pressure patterns (e.g. Zangovil et al., 2003; Liwei et al., 2006; Vide et al., 2008; Feldstein \& Dayan, 2008; Cassano \& Cassano, 2010; Lisa, 2010; Jahanbakhsh \& Zolfaghari, 2002; Habibi, 2007; Mofidi et al., 2007; Asakereh et al., 2010; Fattahi \& Ghannad, 2010).

High pressure centers (high altitude) and low pressure (low altitude) in sea level maps (upper atmosphere level) are called activity centers. The place and range of these activity centers in various atmospheric levels have significant roles in controlling the climate of their surrounding regions (Wallace \& Gutzler, 1981; Santos, 2004). One of the examples of these pressure centers is the Black Sea, which produces a dynamic system in regional scale obeying general circulation of the atmosphere, and because it is related to air circulation, it occurs generally in cold period of the year in upper troposphere and in daily to annually time scales (Mofidi \& Zarrin, 2006).

It should be noted that most of the conducted studies in the field of pressure patterns in the Black Sea indirectly refer to the Black Sea high pressure and low pressure and sometimes to European high pressure (Fattahi and Salehi Pak, 2009; Asakereh et al., 2010; Nouri \& Ildarmi, 2012) or west of the Caspian Sea high pressure (Razei et al., 2006), while some other studies directly refer to the Black Sea high pressure and low pressure (Trigo et al., 2002; Jahanbakhsh \& Zolfaghari, 2002; Alijani \& Zahedi, 2002; Moradi, 2006; Khoshhal \& Ghanghermeh, 2009; Masoudian, 2009; Barati \& Haidari, 2010).

However, only a few studies have been directly conducted regarding the anomaly of pressure and macro-scale climate systems in the Black Sea and their relationships with variations in climate elements at ground level; most of these studies refer to the integrated role of pressure systems in the Black Sea with other climatic systems. According to UnkasÏevic and Radinovic (2000), there is a highly significant correlation between maximum daily precipitations and monthly average in Belgrade and these situations will be present when a cyclone with center position is placed in Eastern Mediterranean and indeed is extended out in all over (above) the northwest coast of the Black Sea. Stanev and Peneva (2002) studied the response of the Black Sea surface and concluded that by beginning 1870's, there was a strong correlation between the sea level and NAO index. 
Kazmin and Zatsepin (2007) showed that there was a significant correlation between the prevailing wind and NAO index. On the other hand, long-term changes in the winter average temperature in the Black Sea surface have a highly significant correlation with air temperature, while strengthening or weakening the south wind or north wind cause the temperature of the sea surface to increase or decrease. Mofidi (2000), in a synoptic analysis of the Black Sea influence on Iran's precipitation, concluded that the highest correlation was observed between the Black Sea, region especially the eastern half of the Sea, and Iran's precipitation.

Arabi (2000) expressed some reasons of heavy and excessive precipitation in Iran as the influence of pressure system over the northern half of the country, the flow of very cold air from northern latitudes and moisture transfer from the Caspian Sea and the Black Sea by the anticyclone's move over these areas. In this regard, Karimi and Farajzadeh (2011) considered the Caspian Sea and Persian Gulf proportions in provision of Iran's water precipitation at low levels of the troposphere as less than 3\%.

Based on the monthly maps of sea level pressure and the level of 500 HP Moradi $(2002,2005)$ showed that the heaviest precipitation of southern shores of the Caspian Sea refers to migratory cyclones and anticyclones on the Black Sea. Furthermore, the occurrence of severe precipitation in the north of Iran is accompanied by the ridge on the Black Sea, east to the center of Europe, the Eastern Mediterranean and the presence of a strong trough at the east of the Black Sea.

In a study, Masoudian (2005) indicated that seventeen identified circulation patterns at the level of $500 \mathrm{HP}$; four trough patterns of the Black Sea, Western Mediterranean trough, Syrian trough and Eastern Mediterranean trough enjoy the highest correlation with precipitation in Chaharmahal and Bakhtiari province. According to Kaviani et al. (2007), the circulation pattern of the Black Sea trough, Syrian trough, and the trough pattern of Eastern Mediterranean and the trough pattern of Western Mediterranean are the cause of more than $95 \%$ of basin precipitation. These patterns, in the form of western winds, enter Iran mostly from the Northwest, Southwest and West of the country. Hejazi Zadeh and Fattahi (2007) identified eight main circulation patterns for Iran called circulation pattern with low pressure in the Mediterranean, sub polar low pressure, eastern high pressure, northern high pressure, Eastern Europe high pressure, Siberian high pressure, Central high pressure and integration of Siberian high pressure system with European high pressure system in winter.

Masoudian (2008) showed that the establishment of a high-pressure system over the Black Sea and the spread of Persian Gulf trough cause two-thirds of one-day heavy rain in Iran to occur. Furthermore, forming Iraq trough and creeping of Siberian-Black Sea high pressure tongues into Iran lead to mostly precipitation in the Caspian Sea shores. This system leads to one third of heavy rain in Iran.

According to Barati and Heidari (2010), cold and dry air flow of the Black Sea's entering Iran in spring cause glaciation and frostbite in the west and northwest. Indeed, the contributions of the Black Sea to dispatching precipitation systems in the west of Iran are $27.7 \%, 13.1 \%$, and $2 \%$, respectively. Masoudian and Darand (2011) believed that the intensity of coldness resulted from the prevalence of the integrated Siberian-European high pressure pattern (Black high pressure) over Iran especially its northwest, is so that about $43 \%$ of Iran have the standardized mean temperatures $-2.6 \mathrm{C}^{\circ}$ and $-3.9 \mathrm{C}^{\circ}$.

The objective of the present study is to investigate the temporal behavior of sea level pressure in the Black Sea region in order to reveal the hidden aspects of pressure in this region. Therefore, to investigate the climatic conditions of the region, the influence of other systems prevailing over them which cause the climatic condition to change should not be neglected because changing in climatic elements especially precipitation and temperature in some parts of countries in the neighborhood of the Black Sea are dependent on changing in the Black Sea level pressure. 


\section{Data and Methodology}

\subsection{Investigated Zone}

Because of identifying synoptic systems and learning about the circulation patterns location as well as their influencing, the investigated zone was selected to be wider than the Black Sea region. This framework covers areas between -30-70 ${ }^{\circ}$ longitude east and 20-70 ${ }^{\circ}$ latitude north. Spatial resolution of the climatic data is $2.5 \times 2.5$ degrees of arc and the mentioned framework cover is equal to $21 \times 41$ pixels and includes 861 pixels (Fig. 1).

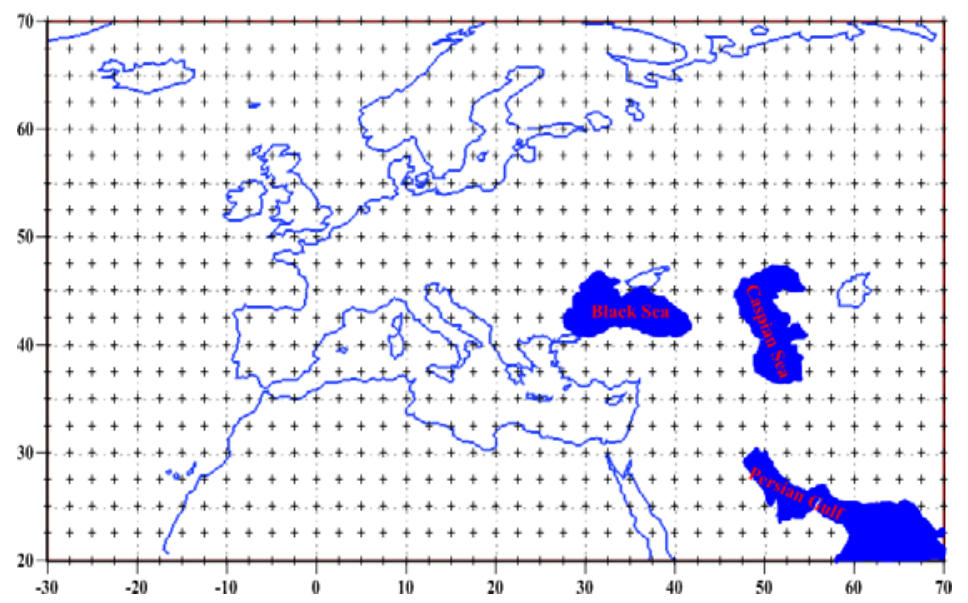

Fig. 1. Position of Investigated Zone with 861 Pixel and Spatial Resolution 2.5×2.5 Degree

\subsection{Data}

In the present study, to achieve a comprehensive view of sea level pressure conditions in the Black Sea region, the data of sea level pressure in Reanalysis II were used. These data were extended from National Centers for Environmental Prediction (NCEP) affiliated with NOAA Earth System Research Laboratory (ESRL). The website is as www.esrl.noaa.gov. The temporal resolution of the data is in the form of daily monitoring in GTM and their spatial resolution is $2.5 \times 2.5$ degrees of arc. The time interval for collecting the data includes 1979 to 2012 (12419 days). Therefore, sea level pressure data in the investigated zone is comprised of a matrix with dimensions of $12419 \times 861$ pixels, which has 12419 temporal pixels and 861 spatial pixels (Table 1). The rows of the matrix represent time according days, and the columns represent space according to $2.5 \times 2.5$ degrees of arc. The resulted matrix is in S-shaped arrangement (Yarnal, 1993; Alijani, 2006).

\section{Table 1}

Sea level pressure database in MATLAB software $(12419 \times 861$ pixels $)$

\begin{tabular}{|c|c|c|c|c|c|c|}
\hline & 1 & 2 & 3 & 4 & 860 & 861 \\
\hline 1 & 1016.67 & 1016.95 & 1016.75 & 1016.38 & 988.125 & 989.25 \\
\hline 2 & 1016.88 & 1017.1 & 1016.98 & 1016.95 & 998.3 & 997.1 \\
\hline 3 & 1016.62 & 1017.35 & 1017.48 & 1017.25 & 1014.4 & 1013.65 \\
\hline 4 & 1017.2 & 1016.92 & 1016.2 & 1015.38 & 1000.98 & 1002.28 \\
\hline 5 & 1015.53 & 1015.02 & 1014.1 & 1012.8 & 1013.9 & 1013.77 \\
\hline 6 & 1015.65 & 1015.12 & 1014.15 & 1012.75 & 1015.55 & 1016.8 \\
\hline 7 & 1017.83 & 1017.62 & 1016.88 & 1016.08 & 1022.95 & 1023.58 \\
\hline$\ldots$ & $\ldots$ & $\ldots$ & $\ldots$ & ...... & ..... & ...... \\
\hline 12416 & 1019.9 & 1020.05 & 1019.62 & 1019.05 & 1017.2 & 1017.6 \\
\hline 12417 & 1018.45 & 1018.7 & 1018.7 & 1018.93 & 1021.17 & 1021.45 \\
\hline 12418 & 1019.4 & 1019.92 & 1020.12 & 1020.37 & 1026.1 & 1027.1 \\
\hline 12419 & 1019.72 & 1020.17 & 1020.2 & 1020.2 & 1026.18 & 1028.02 \\
\hline
\end{tabular}

In the end, a hierarchical cluster analysis by method of Ward Linkage was conducted on the arrangement of Euclidean distance the daily maps of sea level pressure using MATLAB software and 
six synoptic patterns were identified. The reason why the researchers used Ward Linkage technique is that in most of the climatological studies, this technique is used, because in this case, the amount of intergroup variance gets minimized and the homogeneity of the obtained groups gets maximized. Meanwhile, to determine the number of patterns (clusters) the subjective method was used. It means that if the number of clusters had been determined to be less than six clusters, the effective circulation patterns would have merged with each other and if more than this number had been chosen, in addition to repetition and similarity of some of the circulation patterns, the internal homogeneity would have reduced.

\section{Results and Discussion}

By conducting the cluster analysis on the sea level pressure data, first a dendrogram (tree diagram) was drawn and again the maps were divided into six separated pattern (Fig. 2). These six circulation patterns based on the description of the time of occurrence are as follows respectively: fall pattern, spring pattern, transitional pattern, summer pattern, spring-winter pattern, and winter pattern. Temporal transmittal and their occurrence percentage of these patterns during years can be observable in Fig. 3.
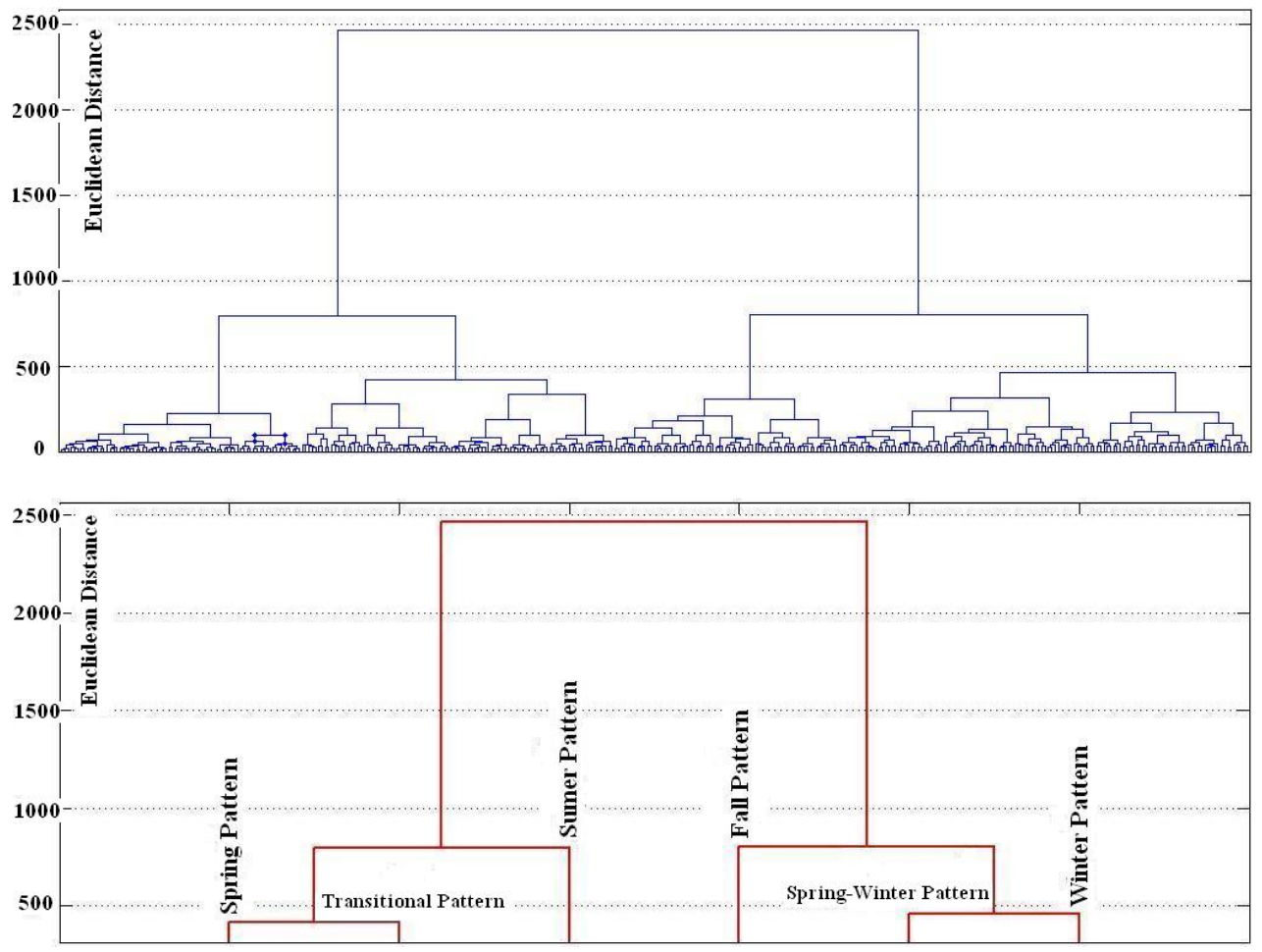

Fig. 2. Cluster Analysis on the Sea Level Pressure Data(Ward Linkage and Euclidean Distance)

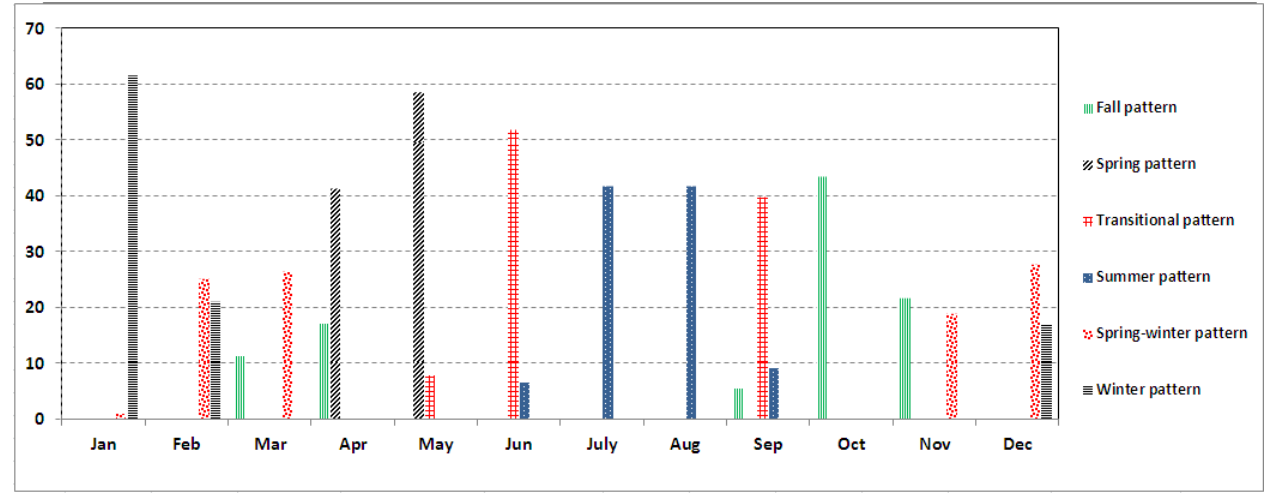

Fig. 3. Occurrence Percentage of Circulation Patterns in During Years 
Then, the daily long-term maps of sea level pressure were drawn using Surfer software and six circulation patterns were identified from their combination:

\subsection{Synoptic Pattern of Red Sea Trough}

In this pattern, a high pressure belt has increased from 20 to 40 degrees latitude, which the spatial range of this high-pressure belt starts from Asia and after crossing over the Caspian Sea and the Black Sea, then continues to the Atlantic Ocean. Meanwhile, a trough occurs in the Red Sea which establishes an allobaric condition in line with the North West - South East. In the prevalence of this trough, large pressure gradient between the Red Sea and the Mediterranean- Black Sea climate is observed (Fig. 4). This pattern is considered as fall because is more frequent occurrence in October and November (Fig. 3).

\subsection{Synoptic Pattern of Iraq Trough}

Temporal distribution of the circulation patterns indicates that this pattern is a spring one, because its maximum occurrence is in April and May (Fig. 3). On the other hand, this pattern is also accompanied by a relatively high-pressure gradient in Iraq and Saudi Arabia. This gradient is the result of the vicinity of Siberian high-pressure core with a low pressure system which has been shaped over the Mediterranean and the Black Sea. However, a Siberian high pressure tongue has penetrated into Iran and encountering European low pressure has created a severe gradient in the west half of Iran (Fig. 5).

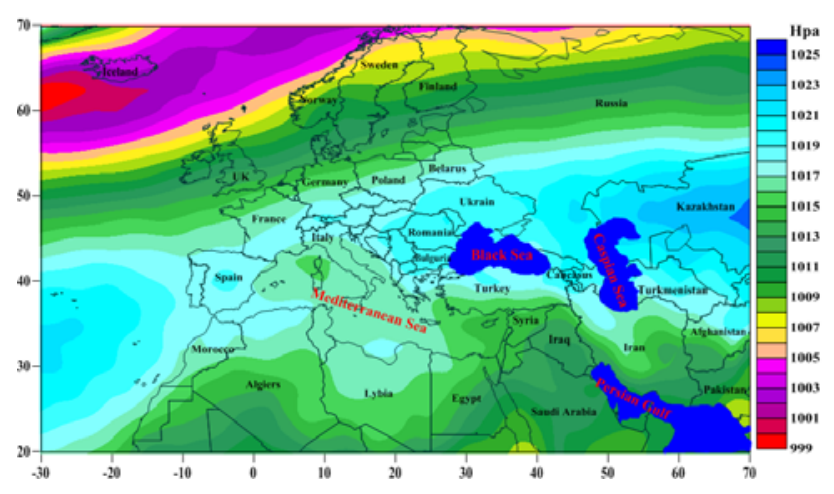

Fig. 4. Synoptic Pattern of Red Sea Trough

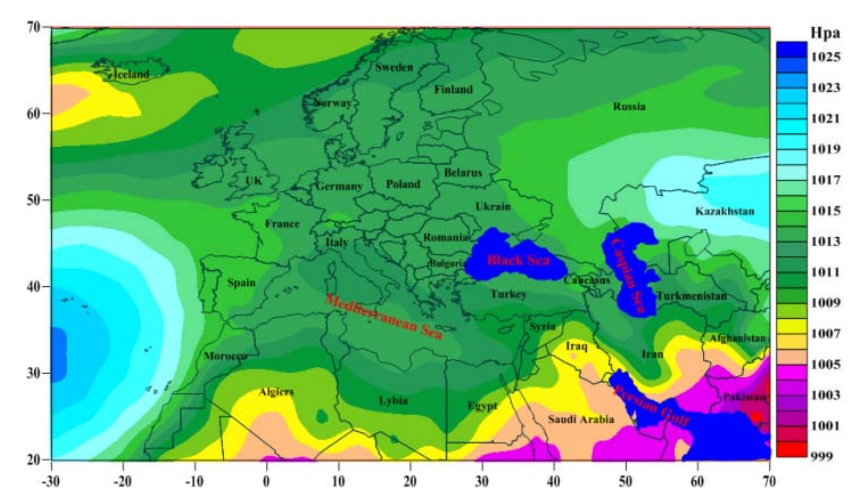

Fig. 5. Synoptic Pattern of Iraq Trough

\subsection{Synoptic Pattern of Persian Gulf Trough}

During the prevalence of this pattern, the Atlantic Ocean high pressure tongue enters Europe from the west. A tongue of this high pressure has been extended up to the Black Sea and an intensive pressure gradient covers in line with west-southeast from Turkey to Iraq because Persian Gulf trough has advanced up to the shores of the Mediterranean (Fig. 6). This pattern is a transitional one and its most frequent occurrence is in June (Fig. 3).

\subsection{Synoptic Pattern of Persian Gulf Strong Trough}

The most important feature of this pattern, on the one hand are the formation and development of Atlantic high pressure and leading its tongues towards Europe; and on the other hand, is the development of strong trough of Persian Gulf. The vicinity of these two systems causes the occurrence of intensive pressure gradient in the west of Iran and the south of Turkey, but in the west and north of the Black Sea, the conditions favor high-pressure (Fig. 7). Evidence suggests that this pattern is totally a summer one (Fig. 3). 


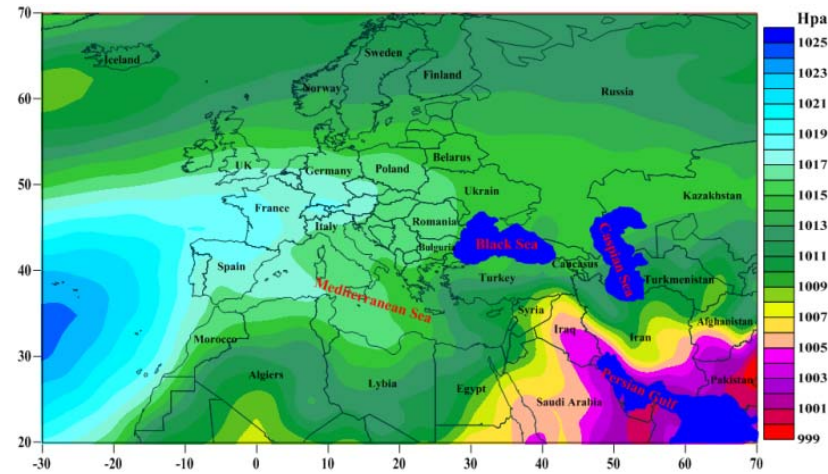

Fig. 6. Synoptic Pattern of Persian Gulf Trough

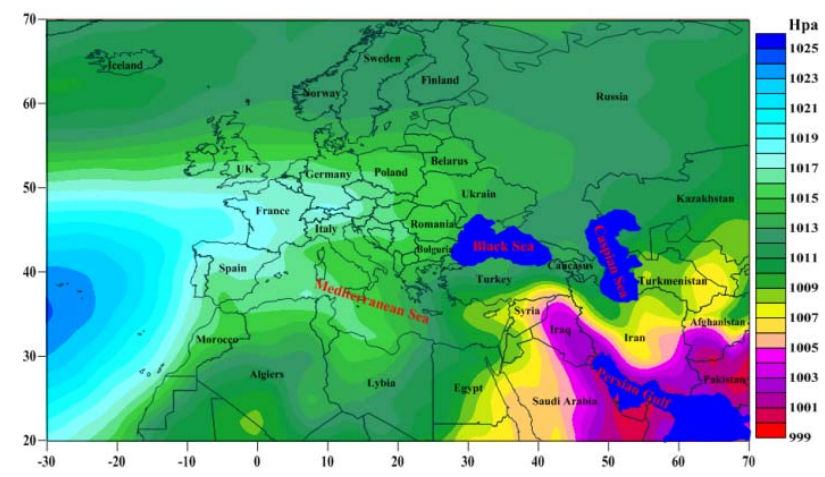

Fig. 7. Synoptic Pattern of Persian Gulf Strong Trough

\subsection{Synoptic Pattern of Caucasian High Pressure}

In this pattern, a tongue from the Siberian high pressure has entered Iran from the west of the Caspian Sea. In the Caucasus region, also a high pressure whose some of tongues have been extended up to Turkey and Iran center, has been formed,. These conditions are representative of reinforcing high pressures surrounding the Black Sea and the Caspian Sea, which cause the formation of intensive gradient and at last atmospheric instability (Fig. 8). More frequent occurrence this pattern is in the cold period (fall and winter) (Fig. 3).

\subsection{Synoptic Pattern of Caucasian Strong High Pressure}

This pattern is a winter one (Fig. 3). In the period of the prevalence of this pattern, SiberianCaucasian-Atlantic high pressure belt appears. The extension of sub polar low pressure and its displacement to lower latitudes pave the path for centralizing high pressure systems between latitudes 20 and 40 degrees so that in the Caucasus region and the west of the Black Sea (Romania and Bulgaria) the high pressures canon intensifies. In this period of time, the Red Sea trough is existent and in its prevailing space, the pressure gradient is observed between the Red Sea and the Mediterranean (Fig. 9).

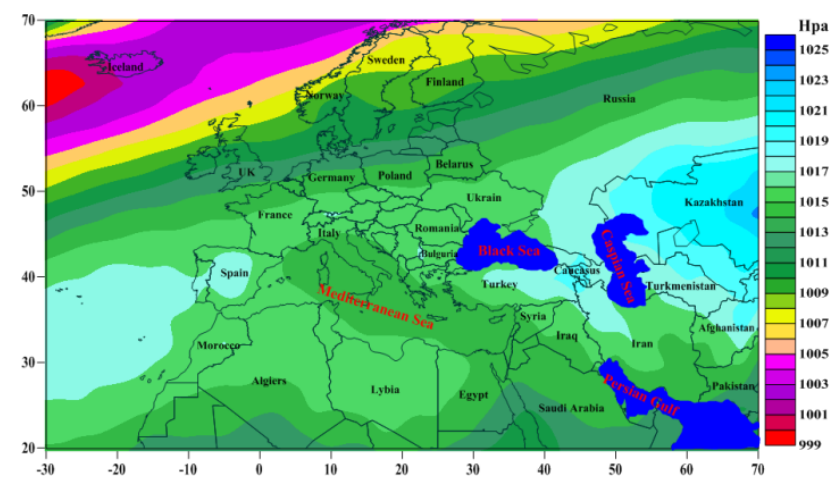

Fig. 8. Synoptic Pattern of Caucasian High Pressure

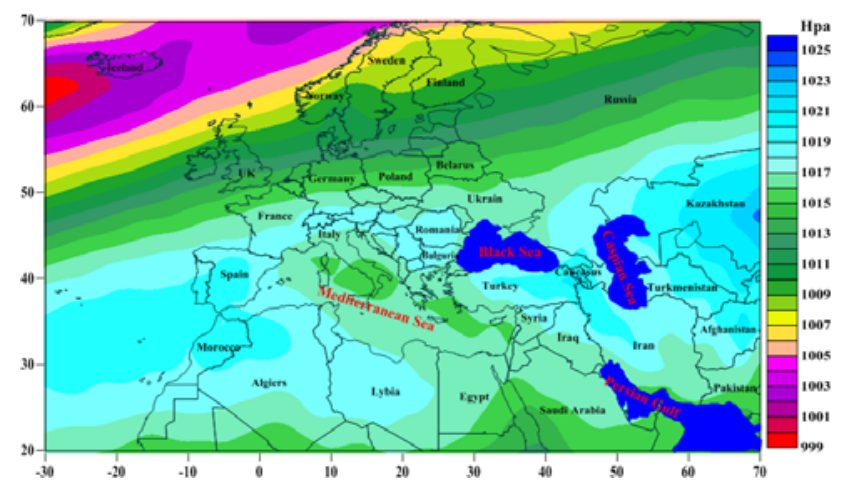

Fig. 9. Synoptic Pattern of Caucasian Strong High Pressure

\section{Conclusions}

The main objective of the present study was to investigate the behavior of the Black Sea high pressure and to attain this objective; the sea level pressure data were used. The findings showed that this system is a transitional one and were not observable in the averaging maps. Nevertheless, by conducting the cluster analysis on the sea level pressure instead of combining weather maps (averaging), it can be possible to categorize the maps and achieve several synoptic patterns. This 
method is very common in synoptic climatology and has confirmed its ability in solving the synoptic problems (Masoudian, 2006). Based on this discussion, six synoptic patterns of sea level pressure which represented the existence of one or several different patterns were identified. Overlapping some of these patterns with other ones is indicative of the very complicated macro systems climatology with each other. This jumbling faces the separation of atmospheric systems from each other with serious problems. However, the existence of interconnection and interaction among Atmosphere - Earth systems should not be neglected.

In addition, the results show that the highest frequency of the occurrence of circulation patterns belongs to the winter synoptic pattern and the lowest to the spring one because the occurrence of circulation pattern in the cold period (fall and winter) enjoys more diversity as a result of extension and reinforcement of the migratory high pressures. To investigate the geographical situation of the pressure systems in the studied region shows that Atlantic and Siberian high pressure centers and sub polar low pressure centers enjoy more centralization and stability, while the high pressure situation of the Black Sea is not centralized in a region. Perhaps this is because that most scholars of climatology call the Black Sea high pressure as European high pressure or west of Caspian Sea high pressure. Also, to accompany the circulation pattern of the Red Sea trough, Iraqi trough and Persian Gulf trough by other high pressure systems such as the Black Sea and the Caucasus results in the occurrence of intensive pressure gradient. It surely will have a significant role in changing or reinforcing climatic elements at ground level.

\section{Acknowledgements}

The authors are grateful to NOAA, for providing NCEP/NCAR reanalysis data.

\section{References}

Alijani, B. (2006). Synoptic Climatology ( $2^{\text {nd }}$ ed.). Samt Publication, Tehran, Iran.

Alijani, B., \& Zahehi, M., (2002). Statistical and synoptic analysis of Azarbaijan area rainfall, Iranian Journal of Research in Geography, 65-66, 202-217.

Arabi, Z. (2006). Synoptic analysis of rainfall in the Period 21 to 26 July 1999 in Iran, Journal of Geographical Researches, 56, 1-15.

Asakereh, H., Khoshraftar, R., \& Sotoudeh, F. (2010). Sea level daily pressure patterns influence on rainfall in September Guilan (2005 - 1976), Journal of Geographic Landscape, 12, 91-112.

Asakereh, H., \& Razmi, R. (2011). Climatology of precipitation in north west of Iran, Iranian Journal of Geography and Development, 25, 137-158.

Barati, G., \& Haidari, I. (2010). Ranking of west precipitation in Iran based on the origin of low pressure precipitation causing, Journal of Geological Research, 2, 61-71.

Cassano, J.J., \& Cassano, E.N. (2010). Synoptic forcing of precipitation in the Mackenzie and Yukon river basins, International Journal of Climatology, 30, 658-674.

Corte, J., Quian, B., \& Xu, H. (1999). Daily precipitation in Portugal and implications for climate change simulated by the second hadley centre GCM. Climatic Dynamics, 15, 921-935.

Fattahi, E., \& Ghannad, H. (2010). Synoptic patterns analysis of dust storms in the south west of Iran. Iranian Journal of Geography, 49-63.

Fattahi, E., \& Salehi Pak, T. (2009). Synoptic analysis of winter frost in Iran. Iranian Journal of Geography and Development, 13, 127-136.

Feldstein, B., \& Dayan, U. (2008). Circum global teleconnections and wave packets associated with Israeli winter precipitation. Quarterly Journal of Royal Meteorological Society, 134, 455-467.

Habibi, F. (2007). Blocking systems role in Cyclogenese on the east Mediterranean and investigation of role in floods west in Iran. Journal of Geographical Researches, 62, 109-127.

Hejazi Zadeh, Z., \& Fattahi, E. (2004). Synoptic patterns analysis of winter precipitation in Iran. Iranian Journal of Geography, 3, 89-107.

Jahanbakhsh, S., \& Zolfaghari, H. (2002). A synoptic analysis of daily precipitation in west of Iran, 
Iranian Journal of Research in Geography, 64-65, 234-258.

Javanmard, S., Babaiyan, I., Jamali, J., Shahabfar, A.R., \& Khazanedari, L. (2003). The correlation between the variability of Kazaghistan-Omman and pricipitation changes in Iran. Iranian Journal of Research in Geography, 71, 134-149.

Karamouz, M., Farahani, M., \& Moridi, A. (2006). Long-term rainfall forecasting using meteorological signals, apply of artificial neural networks (South-East of Iran), The $2^{\text {nd }}$ Conference of Water Resources Management, Technical University of Isfahan, Isfahan, Iran.

Karimi, M., \& Farajzadeh, M. (2011). Moisture flux and spatial-temporal patterns of moisture supply resources in precipitation of Iran. Journal of Geographical Sciences and Applied Research, 22, 109-127.

Kaviani, M., \& Alijani, B. (2003). The Foundation of Climatology ( $9^{\text {th }}$ ed.). Samt Publication, Tehran, Iran.

Kaviani, M., Masoudian, S.M., \& Najafpour, B. (2007). The relationship between geopotential height 500 Hpa circulation patterns and precipitation over Mond basin. Journal of Humanities Researches, 3, 1-12.

Kazmin, A.S., \& Zatsepin, A.G. (2007). Long-term variability of surface temperature in the Black Sea and its connection with the large-scale atmospheric forcing. Journal of Marine Systems, 68, 293301.

Khoshhal, J., \& Ghanghermeh, A.A. (2009). Identify of synoptic patterns causing storm levels on the southern shores of the Caspian Sea. Iranian Journal of Research in Geography, 95, 131-152.

Krichak, S.O., Tsidulko, M., \& Alpert, P. (2000). Monthly synoptic patterns associated with wet/dry conditions in the eastern Mediterranean. Journal of Theoretical and Applied Climatology, 65, 215229.

Li, Y., \& Smith, I. ( 2009). A statistical downscaling model for southern Australia winter rainfall. Journal of Climate, 22, 1142-1158.

Lisa, A. V., Uotila, P., Nicholls, N., \& Lynch, A. (2010). A new daily pressure dataset for Australia and its application to the assessment of changes in Synoptic patterns during the last century. Journal of Climate, 23, 1111-1126.

Liwei, J., Weijing, L, Chen, D., \& Xiaocun, A. (2006). A monthly atmospheric circulation classification and its relationship with climate in harbin. Acta Meteologica Sinica, 20, 402-411.

Masoudian, S.A. (2005). Prediction and estimation of flood in Chahar-Mahalo-Bakhtiyari province, Research Project, a Province of Chahar-Mahalo-Bakhtiyari.

Masoudian, S.A. (2006). Regionalization of water resources zones of Iran using precipitation entropy. Journal of Humanities Researches, 20, 1-15.

Masoudian, S.A. (2008). Synoptic analysis of super heavy rains of Iran. The $3^{\text {rd }}$ Conference of Iranian Water Resources Management, 23 to 25 October 1999, Department of Civil Engineering, Tabriz University, Tabriz, Iran.

Masoudian, S.A., \& Darand, M. (2011). Synoptic analysis of extreme temperature in Iran. Iranian Journal of Geography and Development, 22, 165-185.

Mofidi, A. (2000). Synoptic analysis of the black sea role in the Iran precipitation. M.A Thesis in Natural Geography, Islamic Azad University of Tehran.

Mofidi, A., \& Zarrin, A. (2006). Analysis of nature and structure of low-pressure and high-pressure centers. Journal of Geological Education, 46, 53-61.

Mofidi, A., Zarrin, A., \& Janbaz Ghobadi, G. R. (2006). Synoptic patterns of extreme fall precipitation in the south Caspian Sea. Journal of Earth and Space Physics, 3, 131-154.

Moradi, H. R. (2002). Synoptic analysis of rainfall in the southern shore of the Caspian Sea in sex cold months. Journal of Marine Sciences, 2, 61-72.

Moradi, H. R. (2006). Flood forecasting based on synoptic situation on the southern shore of the Caspian Sea. Geographical Researches, 55, 109-131.

National Center for Environmental Program and National Center for Atmospheric Research Home Page. http://www.esrl.noaa.gov/psd/data/gridded/data.ncep.reanalysis II.pressure.html (April 7, 2013). 
Nouri, H., \& Ildarmi, A.R. (2012). Sea surface level pressures synoptic patterns in heavy and super heavy precipitation events in the southern coasts of Caspian Sea. Geographic Space, 39, 121-137.

Pandzic, K., \& Trninic, D. (2000). Relationship between monthly precipitation, the Sava river discharge and large-scale circulation, Geophysics, 16-17, 53-63.

Razei, T., Mofidi, A., \& Zarrin, A. (2006). Relationship precipitation in Iran with circulation patterns of winter atmospheric over the middle east. Journal of Earth and Space Physics, 3, 121-141.

Santos, J. A. (2004). Climate variability in Europe and its connection to the tropospheric and stratospheric circulations: A case study for Portugal. PhD Thesis, Department of Physic, Technical University of Lisbon.

Shabankari, M., \& Halabian, A. H. (2012). Synoptic analysis of daily rainfall on the southern coast in Iran and their relationship between changes of Sea level pressure. Iranian Journal of Research in Geography, 1, 165-184.

Stanev, E.V., \& Peneva, E.L. (2002). Regional sea level response to global climatic change: Black Sea examples. Global and Planetary Changes, 32, 33- 47.

Trigo, I. F., Bigg, G. R., \& Davies T. D. (2002), Climatology of cyclogenesis mechanisms in the Mediterranean. Monthly Weather Review, 3, 549-569.

UnkasÏevic. M., \& Radinovic, D. (2000). Statistical analysis of daily maximum and monthly precipitation at Belgrade. Theoretical and Applied Climatology, 66, 241-249.

Vicente-Serrano, S. M., \& Lopez-Moreno, J. I. (2006). the influence of atmospheric circulation at different spatial scales on winter drought variability through a semi-arid climatic gradient in northeast Spain. International Journal of climatology, 26,1427-1453.

Vide, M., Lorenzo, J., Sanche, Z., Bustins, A., Lopez, J. A., Cordobilla, M. J., Garcia, A. J., \& Raso, M. (2008). Torrential rainfall in northeast of the Iberian Peninsula: Synoptic patterns and We MO influence. Advances in Science and Research, 2, 99-105.

Wallace, J. M., \& Gutzler, D. S. (1981). Teleconnections in the geopotential height field during the northern hemisphere winter. Monthly Weather Review, 109, 784-812.

Yarnal, B. (1993). Synoptic Climatology in Environmental Studies (1 $1^{\text {st }}$ ed.), Translate by Masoudian, S. A., (2006). University of Isfahan Publication, Isfahan, Iran.

Zangvil, A., Karas, S., \& Sasson, A. (2003). Connection between eastern Mediterranean Seasonal Mean 500 Hpa Height and Sea-Level Pressure Pattern and the Spatial Rainfall Distribution, International Journal Climatology, 23, 1567-1576. 